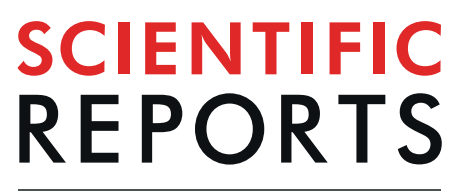

natureresearch

\title{
Simultaneous optimization of parameters influencing organic mulch test using response surface methodology
}

\author{
Saeed Shojaei(i) ${ }^{1}$, Mohammad Ali Hakimzadeh Ardakani ${ }^{1 *}$, Hamid Sodaiezadeh ${ }^{1}$, \\ Mohammad jafari ${ }^{2}$ \& Seyed fakhreddin afzali ${ }^{3}$
}

Wind erosion could be regarded as one of the most important phenomena especially in arid lands in the globe, which destroys vast areas with its rapid growth. Due to global droughts and climate change, vegetation is weakened and soil particles are more easily exposed to wind erosion. Today, various methods have been developed to control wind erosion. One of the most commonly used methods is the use of mulch. Mulch has several types (physical-chemical). The purpose of this research is to make organic mulch with inexpensive and available compounds to prevent environmental pollution as well as preventing wind erosion. For this purpose, Chaff, Manure, Biosolids and Black Strap mixture were used. The surface response method (RSM) was utilized to perform the relevant tests and create optimal situation. In this study, the central composite design (CCD) in RSM modeling was applied to make the optimal experimental conditions of erosion and penetration resistance. The effect of concentration of Chaff, Manure, Biosolids and Black Strap, was evaluated in erosion and penetration resistance and each variable was coded at five levels. The optimum values for penetration resistance of $1.8\left(\mathrm{~kg} / \mathrm{cm}^{2}\right)$ for Chaff, Manure, Biosolids, and Black Strap, were 11.32, 15.72, 19.23 and $4.37 \mathrm{~g}$, respectively. Also, the optimum values of mulch combination for wind erosion of $1.8 \mathrm{~kg} / \mathrm{cm}^{2}$ for Chaff, Manure, Biosolids, and Black Strap, were 12.49, 19.95, 16.71 and $7.15 \mathrm{~g}$, respectively. By increasing the use of these compounds, adhesion and erosion resistance increased and more consumption of Black Strap had a reverse effect. This was due to the loosing of soil particles and creating exponential mode in graphs. According to the results, no particular distinction was found between predicted data by Design-Expert software and experimental data and simulation results can be expressed reliably.

One of the environmental problems in the arid and desert areas of the world that operates externally is the wind erosion and its consequences, such as dust storms and the displacement of massive masses of sand ${ }^{1-3}$. Dust storms destroy lands, reduce visibility (dust concentrations in some cases reach $6 \mathrm{~g} / \mathrm{m}^{3}$ ), and cause the spread of radioactive materialals ${ }^{4}$. The Greenhouse Effect ${ }^{5}$ leads to the transport of salt and chemical substances (herbicides) to the atmosphere, and increases respiratory problems $s^{6,7}$. Over the half past century, various materials have been evaluated to find suitable stabilizers for controlling wind erosion ${ }^{8}$. One common method for controlling the movement of sand is mulching over its surface ${ }^{1}$. The word "mulch" in English means "cover". These materials cover the soil surface as a thin coating and protect soil, water, and plants from damage. This term is more often referred to as soil cover by organic materials such as straw, chaff, plant leaves, and sometimes animal Manures and similar substances. Mulch refers to natural or artificial materials that protect the soil from the damage of various factors such as wind and rain $^{9}$. Mulch reduces water evaporation from the soil surface by creating shadows and also preventing the movement of air on the ground. Therefore, it maintains soil moisture, prevents sudden changes in temperature and increases the fertilization and soil productivity. In general, the purpose of mulching in fixing sandy soils is to increase soil stability in order to provide an opportunity for the establishment of other

${ }^{1}$ Department of Management Arid and Desert Regions, College of Natural Resources and Desert, Yazd University, Yazd, Iran. ${ }^{2}$ Department of Arid and Mountainous Regions Reclamation, Faculty of Natural Resources, University of Tehran, Tehran, Iran. ${ }^{3}$ Department of Natural Resources and Environmental Engineering, College of Agriculture, Shiraz University, Shiraz, Iran. *email: shojaeisaeeds@gmail.com 


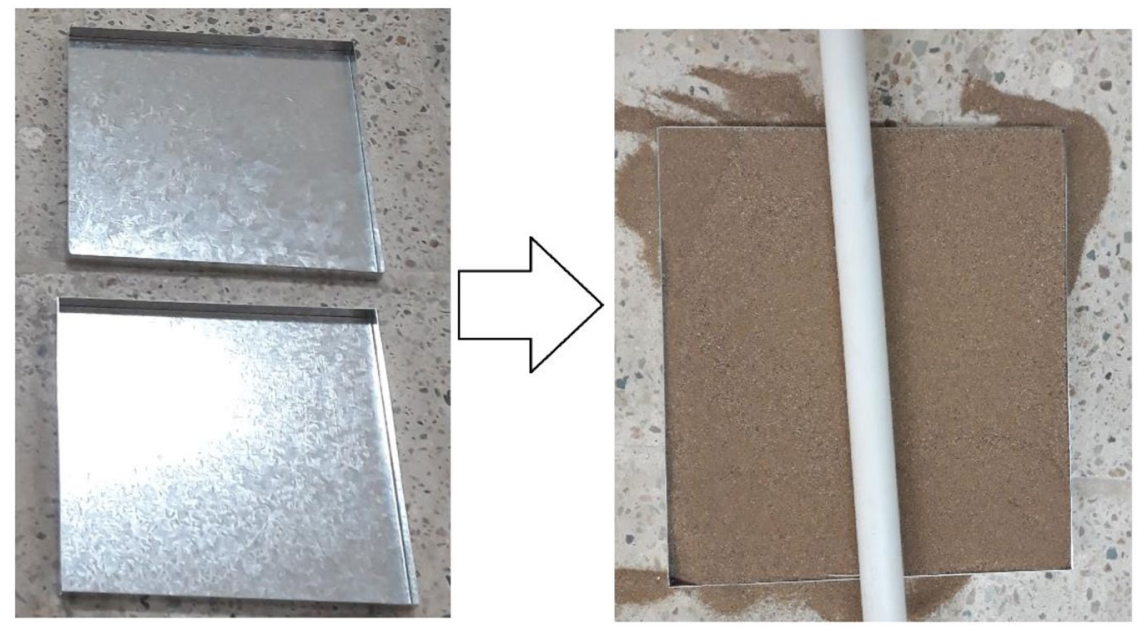

Figure 1. A sample of the trays used in this experiment.

biological activities such as planting and seeding, so that plant species can be located in the field of planting ${ }^{9}$. In different sources, different categorizations are presented for mulches In general, mulches can be divided into two physical and chemical groups ${ }^{10}$ :

1. Physical mulches: These mulches include: (a) biological mulches: Straw and chaff and Manure (b) non-biological mulches: pebbles, solid wastes, clay and cement types.

2. Chemical mulches: These mulches include: (a) oil mulches.; (b) Non-oil mulches

Oil mulches: It is referred to oil products made of hydrocarbon mixtures and used to cement sand particles. However, due to high costs of oil materials and environmental issues, they are not used any more.

Non-oil mulches: include all materials or coatings used to prevent water evaporation, weed growth, and generally to increase soil yields. Non-oil mulches include various synthetic chemical polymers, lime, gypsum, and herbal gums.

$V{ }^{2} \mathrm{zi}^{11}$ in an examination of the use of oil mulch in controlling wind erosion and stabilizing the sand, states that oil mulch is bitumen-like. Therefore, their dark color causes the area to be warmed up more than the surrounding environment, which eliminates the energy balance of the environment and causes the wind in the region. The use of biologic mulch increases the resistance to dust harvesting and surface resistance (penetration resistance). The penetrometer method is an appropriate method for testing mulch ${ }^{12}$. Soil biologic stabilizers have been considered as new stabilizers and have become increasingly important in recent decades. These stabilizers will allow the soil particles to stick together and maintain moisture. These materials are eco-friendly and have no impact on environment and are part of eco-friendly stabilizers ${ }^{13}$. Examples of stabilizers used to date include: cement mulch mixed with soil ${ }^{14}$, calcareous stabilizers and organic stabilizers ${ }^{15}$. These stabilizers, when mixed with soil, cause adhesion and cation exchange ${ }^{16}$. In researches conducted around the world, mulch tests have been performed as a randomized block and mulch application proposed by the expert without testing all of the interval to determine the amount of mulch use. For example, some researchers have proposed the use of $400 \mathrm{~g}$ Cement $+10 \mathrm{~g} \mathrm{Lime}^{14}, 250 \mathrm{gr}$ Clay $+25 \mathrm{gr} \mathrm{Straw}^{17}$ (Majdi et al. (2005), $250 \mathrm{~g} \mathrm{Dunder}{ }^{18}$, which are examples of different researches in this field. There has not been any specific method to produce mulch, and all provided mulch types are mono structural and not optimized. Therefore, in this research, the purpose is to create mulch using new mixture and formula in order to manage the haze and dust pollution. The selected organic materials are mixed together by the software. Then, based on those results, the best formulation is determined for resistance to erosion and penetration. Considering the application of this new method, the results of this study will greatly help to reduce the damage caused by dust and haze pollution around the world. Is used as a new method.

\section{Materials and methods}

This study was conducted at the research laboratory of Yazd University. In order to carry out this research, dune sand samples were taken from sandy hills (Yazd area) and transferred to the wind erosion laboratory and were used as a test bed and also were mixed with mulch. Then were spread onto the special trays ${ }^{19}$. These trays with dimensions of $25 \times 25 \times 2 \mathrm{~cm}$ were used in the wind tunnel. Then, we filled the trays with filtered sand using $2 \mathrm{~mm}$ sieve and also leveled out the tray surfaces through leveling rods and in the next step, we spread the blended mulch all over over the trays. The trays were made of metal (Fig. 1).

After determining the desired mulch composition, adding $500 \mathrm{~mm}$ of water to these compounds and mixing it completely, the mulch was prepared for spraying onto the trays. The mulch was sprayed on the tray with the aid of a sprinkler. The prepared trays were placed in free air for two days from the time of spraying, to dry completely. In this research, materials used to make mulch were Chaff, Manure, Biosolid and Black Strap.

Tests. Wind tunnel Test. The wind tunnel has a blower with a capacity of $2030 \mathrm{~m}^{3} / \mathrm{h}$, equivalent to $1,218 \mathrm{~m}^{3} /$ min (CFM), 2300 RPM (Revolutions per minute), a current of $0.66 \mathrm{~A}$, and a power of $145 \mathrm{~W}$, which produces wind 


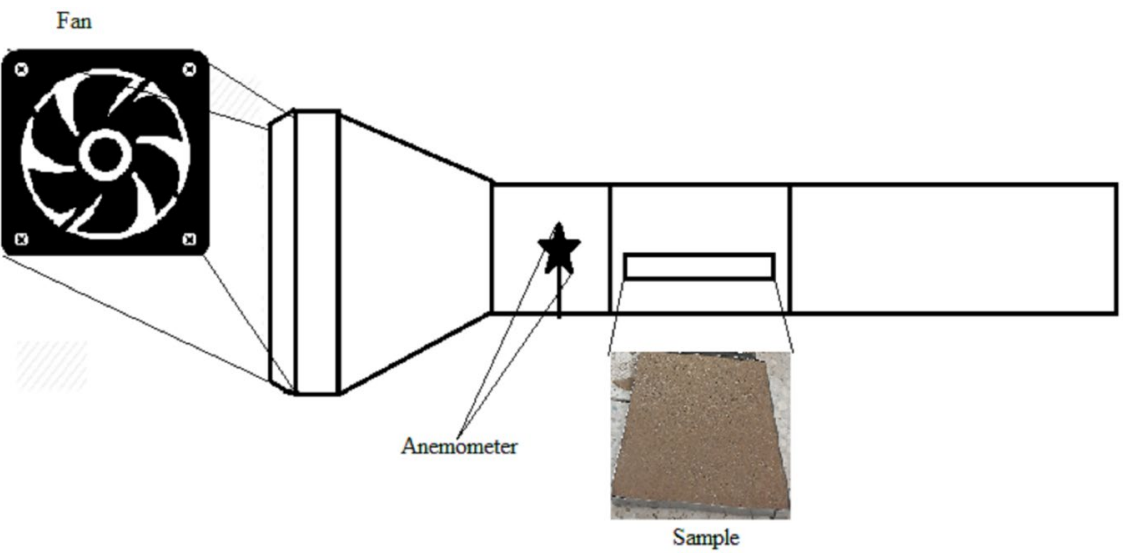

Figure 2. A wind tunnel with an open circuit system.

\begin{tabular}{|l|l|l|l|l|l|l|l|}
\hline & \multirow{2}{*}{ Variables } & \multirow{2}{*}{$\begin{array}{l}\text { Symbol } \\
\text { coded }\end{array}$} & Unit & \multicolumn{2}{|l|}{ Levels } \\
\cline { 5 - 9 } & $\mathrm{-2}$ & $\mathbf{- 1}$ & $\mathbf{0}$ & $\mathbf{1}$ & $\mathbf{2}$ \\
\hline Chaff & $\mathrm{g}$ & $A$ & 4 & 5 & 6 & 7 & 8 \\
\hline Manure & $\mathrm{g}$ & $B$ & 12 & 14 & 16 & 18 & 20 \\
\hline Biosolids & $\mathrm{g}$ & $C$ & 12 & 14 & 16 & 18 & 20 \\
\hline Black Strap & $\mathrm{g}$ & $D$ & 7.5 & 8.5 & 9.5 & 10.5 & 12.5 \\
\hline
\end{tabular}

Table 1. Experimental range and levels of independent process variables.

power with a maximum speed of $12.5 \mathrm{~m} . \mathrm{s}^{-1}$. The motor is mounted on an MDF (Medium-Density Fibreboard) frame with a dimensions of $0.03 \times 0.05 \mathrm{~m}$ which is attached to an MDF sheet with a dimension of $0.3 \times 0.5 \mathrm{~m}$. In order to prevent its possible slipping, two MDF sheets are attached from the top of the frame to the end of the sheet. The samples will be placed in the wind tunnel ${ }^{20}$ for 20 minutes at a speed of $12 \mathrm{~m} . \mathrm{s}^{-1}$ at a height of $15 \mathrm{~cm}$ (Fig. 2).

Penetrometer test. The penetrometer is a device in which the pressure is applied on the surface of the soil with its $1 \mathrm{~cm}^{2}$ tip. When the tip is entered into the soil, the maximum pressure applied to the surface is displayed in $\mathrm{kg} / \mathrm{cm}^{2}$. The penetrometer is used to test the compressive strength of the soil surface, the compressive strength of the crust formed on the soil surface, and the compressive strength of the mulch dispersed on the soil surface ${ }^{21}$.

Response surface methodology (RSM). RSM is a way to study search optimum conditions for a multi-variable system which can optimize conditions. One of the most important advantages of RSM is to reduce the number of experiments and as a result, it could save costs and it would be less time-consuming. Also, there is the chance to analyze the effects of different factors over each other and changing trends. Since we need RSM to carry out the experiments, we have to know the design of experiment. The design of experiments involves a series of experiments that deliberately create changes in the process input variables, and in this way, the amount of resulting variation in the process output response is detected and identified ${ }^{22}$. The process can be thought of as a combination of devices, methods, and individuals that converts input materials into an output product ${ }^{23}$. This output product has one or more qualitative attributes or visible responses. Some process variables are controllable and others are uncontrollable (although they can be controlled in test conditions). In this method, the effect of all factors is considered. We used Design-Expert to design and analyze the experiment and the results are given to the software. It calculates one-way analysis of variance to check the preciseness of the experiment ${ }^{24}$. Then, the model and formulation are carried out. Finally, the software optimizes the factors in the experiment. All the results of penetrometer and wind tunnel tests were introduced into Design-Expert software. The design of experiments was done based on the number of treatment which are entered in the software and the data were given to the software. Then, based on the data in the experiment, the best mathematical model was chosen and then diagrams were illustrated, optimized and finally the formula was presented.

Experimental design and data analysis. As the research tasks are developing, it is required to use some methods to reduce the number of experiments and reach the final results as quickly as possible. Therefore, a proper design for experiments can not only lower the costs, but also paves the way for more reliable results. An exact way to design such experiments is to use Design-Expert which has been applied in this research.

In this research, four independent variables including Chaff, Manure, Biosolide and Black Strap were examined and each variable was coded at five levels (Table 1). The test was designed by Design-Expert 10.0.830 software. Equation 1 was used to code variables: 


\begin{tabular}{|c|c|c|c|c|c|c|c|c|c|c|c|}
\hline \multirow[b]{2}{*}{ Source } & \multicolumn{5}{|c|}{ Penetrometer } & \multicolumn{6}{|c|}{ Wind Erosion } \\
\hline & $\begin{array}{l}\text { Sum of } \\
\text { squares }\end{array}$ & df & \begin{tabular}{|l|} 
Mean \\
square
\end{tabular} & F-value & P-value & $\begin{array}{l}\text { Sum of } \\
\text { squares }\end{array}$ & df & $\begin{array}{l}\text { Mean } \\
\text { square }\end{array}$ & F-value & P-value & Remarks \\
\hline Linear & 0.22 & 20 & 0.019 & 40.05 & $<0.0001$ & 160.600 & 4 & 30.170 & 17.555 & $<0.0001$ & - \\
\hline $\begin{array}{l}\text { 2FI (two factor } \\
\text { interactions) }\end{array}$ & 0.20 & 14 & 0.016 & 1.10 & 0.04000 & 0.250 & 6 & 0.050 & 0.021 & 1.0000 & - \\
\hline Quadratic & 0.9 & 10 & 0.07 & 5.00 & 0.0066 & 46.698 & 4 & 14.500 & 56.485 & $<0.0001$ & Suggested \\
\hline Cubic & 0.040 & 2 & 0.020 & 0.60 & 0.3547 & 2.368 & 8 & 0.590 & 4.585 & 0.0412 & Aliased \\
\hline
\end{tabular}

Table 2. Statistical parameters for sequential models.

$$
Z_{i}=\frac{x_{i}+x_{o}}{\Delta x_{i}}
$$

where: In this relation, $Z_{i}$ is the value of the encoded independent variable, $x_{i}$ and $x_{0}$ are the actual values of the independent variables, $x_{0}$ is the central point, and $\Delta x_{i}$ is amount of variation.

The best method for assessing the fitness quality of the model is to use ANOVA analysis for test results ${ }^{24}$. After entering the results into Design-Expert software, the quadratic model was considered as the ideal model for resistance to penetration and wind erosion among different mathematical models. The quadratic equation is shown in Eq. (2):

$$
Y=b_{0}+\sum_{i=1}^{4} b_{i} x_{i}+\sum_{i=1}^{4} b_{i i} x_{i}^{2}+\sum_{i=1}^{3} \sum_{j=i+1}^{4} b_{i j} x_{i} x_{j}
$$

where: $Y$ is the predicted response, $b_{0}$ is the coefficient of width from the origin, $b i$ represents the linear coefficient of the parameters, $b_{i i}$ is the second-order interaction coefficient, $b_{i j}$ is the second-order coefficient, and $x_{i}$ and $x_{j}$ are independent encoded variables ${ }^{25,26}$. As shown in Table 2, the P-value is calculated for each model and the best model is also chosen based on the conditions.

\section{Results and discussion}

Statistical analysis. Experimental data are presented for the permeability and wind erosion of the produced mulch in Table 3. The final model for predicting the permeability and wind erosion is shown in Equations 3 and 4:

\begin{tabular}{|l|l|}
\hline Penetrometer $=1.60+0.10 A+0.1 B+0.10 C+0.19 D+0.018 A B-0.022 A C+0.022 A D-0.0140 B C+0.0140 B D-$ \\
$0.040 C D+3.10 A^{2}+3.10 B^{2}+0.030 C^{2}+0.075 D^{2}(3)$ & $A:$ Chaff $B:$ Manure $C:$ \\
\hline Wind tunnel $=20-1.48 A-0.2 B-0.35 C-2.55 D+0.14 A B+0.14 A C+0.63 A D+0.63 B C+0.07 B D+0.09 C D-$ & Biosolids $D:$ Bla ck Strap \\
$0.72 A^{2}+8.29 B^{2}-4.6 C^{2}-1.5 D^{2}(4)$ &
\end{tabular}

The analysis of variance and factor values are displayed in Table 4 . The calculated F-values for permeability and wind erosion (26.241 and 59.069 respectively) are more than the tabular values. The calculated $\mathrm{R}^{2}$ values for permeability and wind erosion are 0.9541 and 0.9710 , respectively, which indicates the acceptable accuracy of the model in estimating the predicted data from the experimental data.

The Adj- $\mathrm{R}^{2}$ values for permeability and wind erosion ( 0.9200 and 0.9600 respectively) confirms the proposed model. By measuring the signal-to-noise ratio, the accuracy of the model can be shown, which should be greater than 4. In this study, this ratio is 21.521 and 30.514 for the values of permeability and wind erosion, respectively which indicates a high degree of accuracy ${ }^{24}$.

Fig. 3 shows the results of the actual (experimental) values of penetrometer and wind tunnel against the predicted values of the response surface method. The values of the determination coefficient $\left(\mathrm{R}^{2}\right)$ for pentameter and wind tunnel, are 0.9541 and 0.9710 , respectively, which indicate the reasonable precision between the data and the model.

Interaction between influencing factors. The three-dimensional (3D) response surface plots were used to understand the interactions of the studied factors in mulch on the responses and relationships between them. Figure 4, the 3D response surface plots function was utilized to investigate the interaction between the materials used in mulch on the penetration resistance.

Soils that are stabilized with the combination of mineral mulches and organic matter (biopolymer) show higher resistance to storm and surface resistance (maximum penetration force) due to increased surface penetration (maximum penetration strength) and high adhesion. The penetrometer test is a suitable method for determining resistance to erosion ${ }^{13}$.

In Fig. 4(a-c), the interaction between Chaff with the Manure, Biosolids, and Black Strap content is investigated for resistance to permeability. As is shown, with increasing the amount of Chaff in the mulch, the resistance to penetration is also increased, and consequently, the direct effect is also observed. The effect of Blackstrap on the resistance to penetration in organic mulch was higher than Chaff, Manure, and Biosolids. If the amount of Chaff is considered constant, with an increase in the amount of Black Strap, the soil compaction was less. The reason for this is its fluidity property and the need for more time to dry. 


\begin{tabular}{|c|c|c|c|c|c|c|c|c|}
\hline \multirow{2}{*}{\multicolumn{5}{|c|}{ Variables }} & \multicolumn{4}{|l|}{ Response } \\
\hline & & & & & \multicolumn{2}{|c|}{ Penetrometer $\left(\mathrm{kg} / \mathrm{cm}^{2}\right)$} & \multicolumn{2}{|c|}{ Wind Erosion $\left(g / m^{2} h\right)$} \\
\hline Run & $A$ & $B$ & $C$ & $D$ & Experimental & Predicted & Experimental & Predicted \\
\hline 1 & 5 & 14 & 14 & 8.5 & 1.1 & 1.23 & 24.60 & 24.66 \\
\hline 2 & 7 & 14 & 14 & 8.5 & 1.6 & 1.60 & 21.99 & 22.20 \\
\hline 3 & 5 & 18 & 14 & 8.5 & 1.5 & 1.49 & 24.20 & 26.80 \\
\hline 4 & 7 & 18 & 14 & 8.5 & 1.7 & 1.60 & 21.00 & 20.70 \\
\hline 5 & 5 & 14 & 18 & 8.5 & 1.7 & 1.63 & 23.10 & 22.00 \\
\hline 6 & 7 & 14 & 18 & 8.5 & 1.6 & 1.71 & 20.97 & 20.88 \\
\hline 7 & 5 & 18 & 18 & 8.5 & 1.9 & 1.79 & 22.40 & 22.00 \\
\hline 8 & 7 & 18 & 18 & 8.5 & 1.8 & 1.87 & 18.90 & 19.15 \\
\hline 9 & 5 & 14 & 14 & 10.5 & 1.6 & 1.61 & 18.50 & 18.60 \\
\hline 10 & 7 & 14 & 14 & 10.5 & 2.1 & 2.00 & 15.60 & 15.70 \\
\hline 11 & 5 & 18 & 14 & \begin{tabular}{|l|l}
10.5 \\
\end{tabular} & 2 & \begin{tabular}{|l|}
1.85 \\
\end{tabular} & \begin{tabular}{|l|l}
18.15 \\
\end{tabular} & \begin{tabular}{|l|l|}
18.30 \\
\end{tabular} \\
\hline 12 & 7 & 18 & 14 & 10.5 & 2.3 & 2.27 & 15.12 & 15.44 \\
\hline 13 & 5 & 14 & 18 & 10.5 & 2 & 1.97 & 17.42 & \begin{tabular}{|l|l|}
17.90 \\
\end{tabular} \\
\hline 14 & 7 & 14 & 18 & \begin{tabular}{|l|l}
10.5 \\
\end{tabular} & 2.1 & 2.15 & \begin{tabular}{|l}
15.80 \\
\end{tabular} & \begin{tabular}{|l|l|}
15.09 \\
\end{tabular} \\
\hline 15 & 5 & 18 & 18 & 10.5 & 2.1 & 2.11 & 16.30 & 16.63 \\
\hline 16 & 7 & 18 & 18 & 10.5 & 2.5 & 2.45 & 15.00 & 14.60 \\
\hline 17 & 4 & 16 & 16 & 9.5 & 1.5 & 1.50 & \begin{tabular}{|l|l|}
22.00 \\
\end{tabular} & 23.22 \\
\hline 18 & 8 & 16 & 16 & 9.5 & 2 & 1.97 & \begin{tabular}{|l|}
15.10 \\
\end{tabular} & \begin{tabular}{|l}
15.80 \\
\end{tabular} \\
\hline 19 & 6 & 12 & 16 & 9.5 & 1.5 & 1.50 & 22.20 & 22.05 \\
\hline 20 & 6 & 20 & 16 & 9.5 & 2 & 1.97 & 20.31 & 20.70 \\
\hline 21 & 6 & 16 & 12 & 9.5 & \begin{tabular}{|l|}
1.7 \\
\end{tabular} & 1.59 & 21.50 & 21.55 \\
\hline 22 & 6 & 16 & 20 & 9.5 & 2.2 & 2.18 & 20.15 & 20.45 \\
\hline 23 & 6 & 16 & 16 & 7.5 & 1.5 & 1.42 & \begin{tabular}{|l|l|}
18.30 \\
\end{tabular} & \begin{tabular}{|l|}
19.67 \\
\end{tabular} \\
\hline 24 & 6 & 16 & 16 & \begin{tabular}{|l|}
12.5 \\
\end{tabular} & 2.3 & 2.22 & 11.42 & 10.76 \\
\hline 25 & 6 & 16 & 16 & 9.5 & 1.6 & 1.60 & 20.00 & 21.00 \\
\hline 26 & 6 & 16 & 16 & 9.5 & 1.5 & 1.60 & \begin{tabular}{|l|l|}
20.00 \\
\end{tabular} & 21.00 \\
\hline 27 & 6 & 16 & 16 & 9.5 & 1.6 & 1.60 & 20.00 & 21.00 \\
\hline 28 & 6 & 16 & 16 & 9.5 & 1.6 & 1.60 & 20.00 & 21.00 \\
\hline 29 & 6 & 16 & 16 & 9.5 & 1.6 & 1.60 & 20.00 & 21.00 \\
\hline 30 & 6 & 16 & 16 & 9.5 & 1.6 & \begin{tabular}{|l|l|}
1.60 \\
\end{tabular} & 20.00 & 21.00 \\
\hline
\end{tabular}

Table 3. Response surface central composite design and experimental and predicted responses.

Research has been conducted on the role of Chaff in permeability resistance. For example, researchers conducted experiments on the effect of Chaff mulch on the resistance to permeability in various soils of America. The amount of mulch used in different soils was two and a half tons of Chaff per acre. The results of the studies are shown that the difference between the resistance to permeability in soils with mulch and non-mulch is quite significant and comparable ${ }^{13}$.

In Fig. 4(a,d,e), the interaction of the Manure parameter with the Chaff, Biosolids, and Black Strap content is investigated for resistance to permeability. As Manure value is raised, the penetration resistance is increased, but this increase was low because, with increasing the amount of Manure in the mulch, the adhesion of soil particles is first increased and then decreased, and the resistance to penetration changed. The effect of Manure on the resistance to penetration in organic mulch is relatively similar to Chaff and have no significant effect on penetration resistance, but the effect of Manure on soil adhesion and penetration resistance were less than Biosolids and Black Strap. Black Strap leads to significant adhesion of soil particles.

In Fig. 4(b,d,f), the interaction of the Biosolids parameter with the Chaff, Manure, and Black Strap content are investigated for resistance to permeability. By increasing the Biosolids content, the resistance to penetration is increased. The effect of Biosolids on the resistance to penetration in the organic mulch is relatively similar to that of Chaff and Manure, but Black Strap leads to more adhesion of soil particles compared to Biosolids.

Arid soils often have the lowest amount of organic matter. Therefore, due to the limited resources of Manure, the use of other organic Manure sources, such as Biosolids, is desirable ${ }^{21,23}$. Sewage sludge is rich in plant required elements and is therefore considered to be a low-cost Manure by agricultural experts. Also, an increase of 5\% Biosolids increased the hydraulic conductivity of soil in silt loam tissue ${ }^{27}$, as well as soil stability, improve specific mass and soil porosity is increased. By improving these factors, the strength of the soil surface layer is increased (penetration resistance) and the wind erosion is decreased ${ }^{28}$.

In Fig. 4(c,e,f), the interaction of the Black Strap parameter with Chaff, Manure, and Biosolids are investigated for resistance to permeability. By adding the value of Black Strap, the penetration resistance is increased due to the high adhesion properties of this material in compressing the soil. The effect of Black Strap on the resistance 


\begin{tabular}{|c|c|c|c|c|c|c|c|c|c|}
\hline \multirow[b]{2}{*}{ Source } & \multirow[b]{2}{*}{ df } & \multicolumn{4}{|l|}{ Penetrometer } & \multicolumn{4}{|c|}{ Wind Erosion } \\
\hline & & $\begin{array}{l}\begin{array}{l}\text { Sum of } \\
\text { squares }\end{array} \\
\end{array}$ & $\begin{array}{l}\text { Mean } \\
\text { square }\end{array}$ & F-value & P-value & $\begin{array}{l}\text { Sum of } \\
\text { squares }\end{array}$ & Mean square & F-value & P-value \\
\hline Model & 14 & 3.419 & 0.186 & 26.241 & $<0.0001$ & 312.123 & 16.503 & 59.069 & $<0.0001$ \\
\hline A & 1 & 0.444 & 0.457 & 47.777 & $<0.0001$ & 60.807 & 53.227 & 148.425 & $<0.0001$ \\
\hline B & 1 & 0.340 & 0.298 & 36.152 & $<0.0001$ & 1.420 & 1.140 & 3.871 & 0.0601 \\
\hline $\mathrm{C}$ & 1 & 0.530 & 0.381 & 63.469 & $<0.0001$ & 2.697 & 2.819 & 9.206 & 0.0081 \\
\hline $\mathrm{D}$ & 1 & 1.316 & 1.209 & 170.115 & $<0.0001$ & 132.874 & 101.968 & 525.369 & $<0.0001$ \\
\hline $\mathrm{AB}$ & 1 & 0.003 & 0.003 & 0.342 & 0.5003 & 0.050 & 0.050 & 0.150 & 0.6521 \\
\hline $\mathrm{AC}$ & 1 & 0.025 & 0.028 & 3.203 & 0.0885 & 0.050 & 0.050 & 0.150 & 0.6521 \\
\hline $\mathrm{AD}$ & 1 & 0.025 & 0.028 & 3.113 & 0.0885 & 0.050 & 0.050 & 0.150 & 0.6521 \\
\hline $\mathrm{BC}$ & 1 & 0.003 & 0.003 & 0.322 & 0.5963 & 0.050 & 0.050 & 0.150 & 0.6521 \\
\hline $\mathrm{BD}$ & 1 & 0.025 & 0.027 & 0.300 & 0.5789 & 0.050 & 0.050 & 0.150 & 0.6521 \\
\hline $\mathrm{CD}$ & 1 & 0.000 & 0.000 & 3.090 & 0.0888 & 0.050 & 0.050 & 0.150 & 0.6521 \\
\hline $\mathrm{A}^{2}$ & 1 & 0.026 & 0.023 & 0.060 & 0.7184 & 8.975 & 8.895 & 30.521 & $<0.0001$ \\
\hline $\mathrm{B}^{2}$ & 1 & 0.140 & 0.162 & 0.060 & 0.7144 & 0.003 & 0.002 & 0.008 & 0.8882 \\
\hline $\mathrm{C}^{2}$ & 15 & 0.122 & 0.009 & 3.555 & 0.0854 & 0.000 & 0.000 & 0.001 & 0.8974 \\
\hline $\mathrm{D}^{2}$ & 10 & 0.113 & 0.012 & 16.650 & 0.0006 & 61.400 & 60.885 & 302.125 & $<0.0001$ \\
\hline Residual & 5 & 0.000 & 0.000 & & & 4.448 & 0.358 & & \\
\hline Lack of Fit & 29 & 2.733 & 0.143 & & & 4.258 & 0.436 & & \\
\hline Pure Error & 14 & 2.616 & 0.387 & & & 0.000 & 0.000 & & \\
\hline Cor Total & 1 & 0.344 & & & & 250.700 & & & \\
\hline \multicolumn{10}{|c|}{ Model Summary Statistics } \\
\hline \multirow{3}{*}{\multicolumn{2}{|c|}{ Precision }} & Penetrometer & & & & & Wind Erosion & & \\
\hline & & $\mathrm{R}^{2}$ & Adj- $R^{2}$ & Adequate Precision & & & $\mathrm{R}^{2}$ & Adj- $R^{2}$ & Adequate Precision \\
\hline & & 0.9541 & 0.9200 & 21.521 & & & 0.9710 & 0.9600 & 30.514 \\
\hline
\end{tabular}

Table 4. Analysis of variance (ANOVA) results of quadratic model to Penetrometer and Wind Erosion.

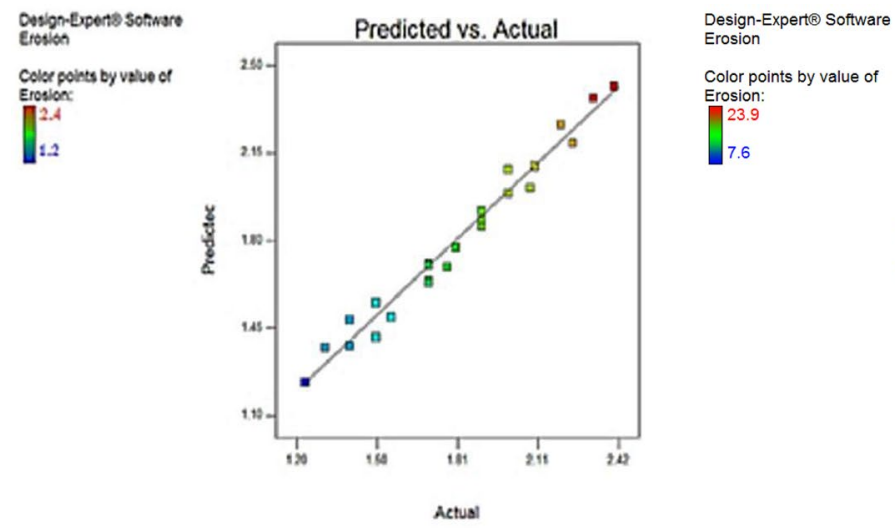

Penetrometer

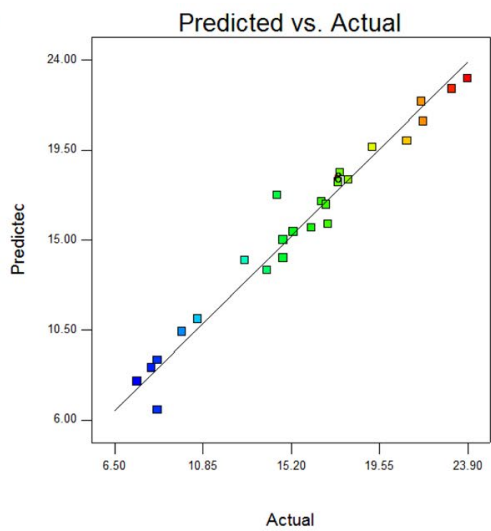

Wind erosion

Figure 3. Scatter plot of predicted value vs actual value from RSM design.

to penetration in organic mulch was higher than that of all used materials (Chaff, Manure, and Biosolids). Khalili Moghadam et al..$^{18}$ conducted a study in Khuzestan with the aim of making mulch from sugar cane residues and comparing it with oil mulch. In this study, the composition of different percentages of sand and sugar cane residues was used. They selected seven compounds. This experiment was conducted as a factorial in a thoroughly randomized mode. In the laboratory, using the mulch spray, the shifting sands was sprayed on the bed. The shear strength and soil penetration resistance of each treatment were measured using a vane shear device. The results represented that by increasing the thickness of the mulch layer, the shear strength and penetration resistance is increased. The combination of $250 \mathrm{~g}$ of sugar cane residues has a better result.

In Fig. 5(a-c), the interaction of the Chaff parameters and Manure, Biosolids, and Black Strap content is investigated for wind erosion. As shown, with increasing the amount of Chaff in the mulch, the wind erosion is also decreased, and so direct effect is observed. The effect of Black Strap on wind erosion resistance in organic mulch was higher than that of Chaff, Manure, and Biosolids, and the rate of wind erosion is significantly reduced. 


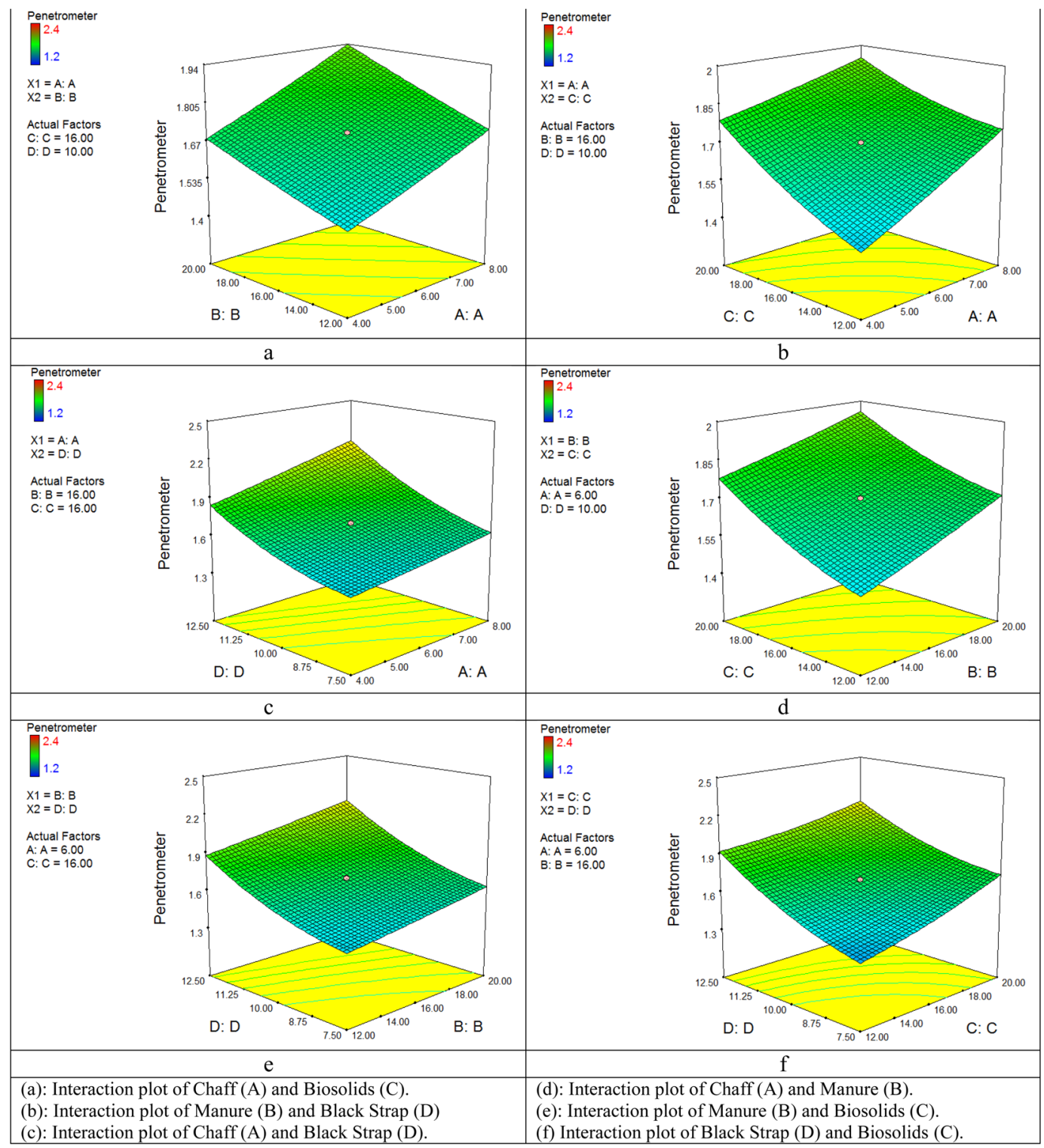

Figure 4. Response surfaces plot on Penetrometer.

If the amount of Chaff is considered constant, with an increase of the Black Strap, the wind erosion of the soil is decreased with a steep gradient.

Adelpor et al., ${ }^{29}$ examined the effect of Straw application on erosion control in different regions. First, according to the amount of Straw, areas are divided into three regions: poor regions (less than $20 \%$ of Straw in the whole region), moderate (20-40\% Straw in the whole region), and good areas (more than $40 \%$ of Straw in the whole region) in terms of plant residues. The results showed that lands with low Straw content have a significant soil resistance to erosion ${ }^{28,30}$.

In Fig. 5(a,d,e), the interaction of Manure parameters with Chaff, Biosolids, and Black Strap is investigated for the reduction of wind erosion. By increasing the amount of Manure, wind erosion is decreased, but this decrease was low because, by increasing the amount of Manure in the mulch, the adhesion of soil particles first is increased and then decreased and causes the change of wind erosion. The effect of Manure on the rate of wind erosion in organic mulch is relatively similar to that of Chaff and has no significant effect on reducing wind erosion, but the effect of Manure on reducing the wind erosion of soil particles compared to the Biosolids and the Black Strap was very low. Black Strap leads to significant adhesion of soil particles and reduced the wind erosion. The effect of Manure and Biosolids on the reduction of wind erosion was insignificant, which can be ignored (Fig. 5). In Fig. 5(b,d,f), the interaction of Biosolids with Chaff, Manure, and a Black Strap on the reduction of wind erosion are investigated. The results showed that by increasing the amount of Biosolids, the wind erosion did not change much. The effect of Biosolids on reducing wind erosion in an organic mulch is almost the same as that of Manure, but the changes in the reduction of wind erosion in the Chaff and the Black Strap were higher. 


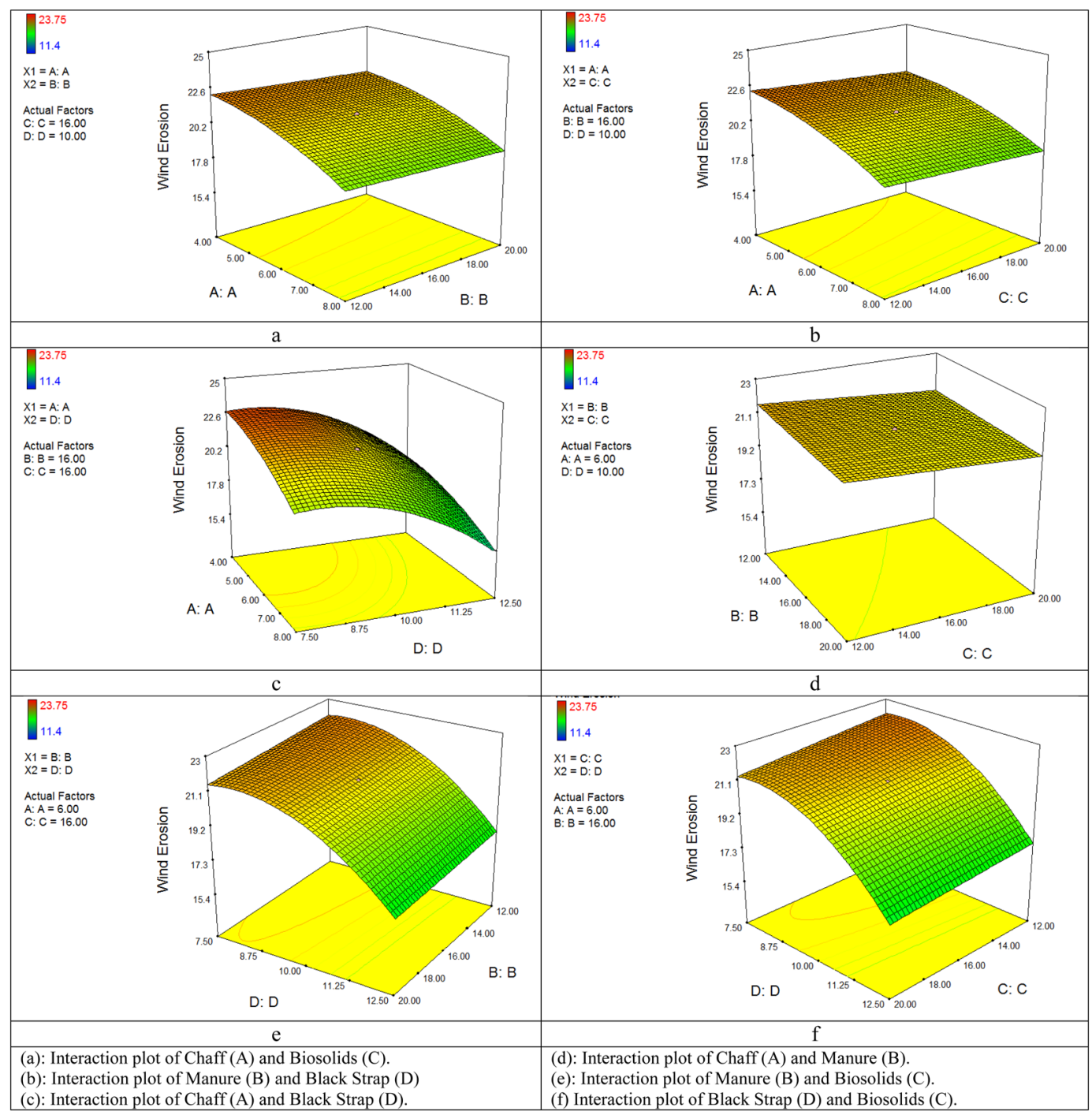

Figure 5. Response surfaces plot on Wind erosion.

Hosseini et al., ${ }^{21}$ investigated the capability and effectiveness of Manures as an anti-erosion agent. The results showed that soil treated with a mixture of water and Manure forms a shell on the soil surface. Two types of Manures (compost and Biosolids) were compared in two roughness of the soil surface (flat and rough). Wind erosion in non-treated soil at $6 \mathrm{~m} . \mathrm{s}^{-1}$ wind speed began on both flat and rough soil surface, while after using the Manure, the wind erosion rate reached $14-12 \mathrm{~m} . \mathrm{s}^{-1}$. There was no significant difference between the wind erosion of two Manures ${ }^{21}$.

In Fig. 5(c,e,f), the interaction of the Black Strap parameter with Chaff, Manure, and Biosolids on the reduction of wind erosion are investigated. By increasing the amount of Black Strap, the wind erosion is reduced. The reason for this is the high adhesion properties of this material, which creates a crust on the surface layer of the soil and reduced the wind erosion. The effect of the Black Strap on reducing the wind erosion in the organic mulch was higher than that of all used materials (Chaff, Manure, and Biosolids). Allahdady et al., ${ }^{31}$ investigated the Black Strap resistance in particle adhesion and increased tensile strength and separation of particles from a number of natural substances (natural fibers, poly-latex, and sugar cane residues). They concluded that, given that the Black Strap has an adhesion property, it is shown a better result in terms of tensile strength, which is consistent with the findings of this study ${ }^{31}$.

Farahmehr et al., ${ }^{32}$ investigated the clay-limestone mulch, sugar cane residues, gravels, steel slag, calcium and magnesium chloride, Poly-latise, and polyvinyl acetate for stabilizing shifting sands. These mulches were examined in laboratory and environment. Their results showed that chemical mulches, although have greater adhesion, resistance to penetration, and wind erosion, cause pollution of the environment. Organic mulches, however, can add nutrients to the soil, and they can be effective in soil stability against wind erosion ${ }^{33}$.

Optimization of reaction. The main purpose of RSM is to choose factors on order to reach the maximum response. In numeral optimization, Design-Expert is used to analyze the factor and response. Each goal could be 


\begin{tabular}{|c|c|c|c|c|c|c|}
\hline \multirow[b]{2}{*}{ Exp. } & \multicolumn{4}{|c|}{ Optimal conditions } & \multicolumn{2}{|l|}{ Penetrometer } \\
\hline & $D$ & $C$ & $B$ & $A$ & Experimental (\%) & Predicted (\%) \\
\hline 1 & 11.50 & 16.60 & 18.33 & 4.89 & 90.80 & 92.50 \\
\hline 2 & 9.56 & 20.11 & 16.54 & 8.20 & 90.40 & 91.30 \\
\hline 3 & 12.20 & 20.00 & 15.70 & 6.69 & 90.20 & 90.10 \\
\hline
\end{tabular}

Table 5. Optimum conditions derived by RSM for Resistance to Penetrometer.

\begin{tabular}{|c|c|c|c|c|c|c|}
\hline \multirow[b]{2}{*}{ Exp. } & \multicolumn{4}{|c|}{ Optimal conditions } & \multicolumn{2}{|l|}{ Wind Erosion } \\
\hline & $D$ & C & $B$ & $A$ & Experimental (\%) & Predicted (\%) \\
\hline 1 & 13.00 & 18.90 & 17.70 & 8.18 & 91.40 & 91.51 \\
\hline 2 & 10.99 & 14.05 & 14.20 & 8.27 & 90.90 & 91.00 \\
\hline 3 & 14.08 & 17.65 & 20.77 & 8.44 & 90.80 & 91.00 \\
\hline
\end{tabular}

Table 6. Optimum conditions derived by RSM for Resistance to Wind tunnel.

used by this software to maximize, minimize, and target in the studied span. In this study, in order to minimize the value of Chaff, Manure, Biosolids, and Black Strap and get the best results in terms of soil resistance and less wind erosion, we used optimization. It is possible to control the value of the materials through optimization which could be used in national and international projects. Therefore, after determining the effect of different factors on the penetration resistance of mulch and wind erosion, to determine the best efficiency for conditions (penetration resistance of mulch and wind erosion), certain levels of effective input parameters are selected. So, the ideal conditions for Chaff, Manure, Biosolids, and Black Strap are chosen without any restrictions on consumption. According to the results obtained by the software, three optimized combinations suggested by the software were chosen and then they were tested and evaluated again. The optimal values of the variables are presented in Tables 5 and 6. The maximum values for infiltration resistance for organic mulch for Chaff, Manure, Biosolids, Black Strap are $4.84 \mathrm{~g}, 18.33 \mathrm{~g}, 16.60 \mathrm{~g}$, and $11.50 \mathrm{~g}$ respectively and the result was $90.80 \%$. Moreover, the maximum values of erosion resistance in organic mulch for Chaff, Manure, Biosolids, and Black Strap are $8.18 \mathrm{~g}$, $17.70 \mathrm{~g}, 18.90 \mathrm{~g}$, and $13.90 \mathrm{~g}$ and the result was $91.40 \%$.

The results showed that the difference between the percentages of predicted data and calculated data to optimize mulch mixture for the values of penetrometer and wind erosion were low which shows a high accuracy of the software in this research (there was below $2 \%$ difference). The results for optimization to create a resistant layer against penetration showed that Black Strap creates a resistant compound, and as Black Strap is used less in the compound, the values for Biosolids and Chaff are increased so that it can rise soil resistance. According to the optimization results, Black Strap was the most efficient mulch mixture to increase the surface resistance. However, the results for reducing wind erosion also showed that it is required to use constant value of Chaff in the mulch because of its properties (clods, and size of particles). Also, Black Strap creates a resistant layer, and by decreasing Black Strap, Biosolids must be used more in order to increase the resistance of mulch against erosion. The optimization results in using the optimum mixture has been really significant so that the determined result could be obtained by mixing appropriate values of given materials.

\section{Conclusion}

In this study, a central compilation scheme is developed in laboratory conditions to create organic mulch. According to the results of the analysis, the optimum conditions for the compound mulch for compression of $2 \mathrm{~kg} / \mathrm{cm}^{2}$ were $11.50 \mathrm{~g}$ Black Strap, $16.60 \mathrm{~g}$ Biosolids, $18.33 \mathrm{~g}$ Manure, and $4.89 \mathrm{~g}$ Chaff. ANOVA analyzes expresses the accuracy of the statistical importance of the model in connection with the high F-value (26.241), low P-value $(<0.0001), \mathrm{R}^{2}(0.9541 \%)$, and adequate precision (21.521). Also, optimum conditions of mixed mulch for wind erosion $\left(17 \mathrm{~g} / \mathrm{m}^{2} \mathrm{~h}\right.$ ) were obtained $13.00 \mathrm{~g}$ Black Strap, $18.90 \mathrm{~g}$ Biosolids, $17.70 \mathrm{~g}$ Manure, and $8.18 \mathrm{~g}$ Chaff. The ANOVA expresses the accuracy of the statistical importance of the model in relation to the high F-value (59.069), low P-value $(<0.0001), \mathrm{R}^{2}(0.9710 \%)$, and adequate precision $(30.514)$. Due to the fact that the optimum components presented by the software are re-checked and there is no difference between the results, simulation results can be expressed reliably. Given that these compounds are blended with water and the particles of the sand are dissolved rapidly with these compounds, a follicular state occurs on the surface of the soil and forms a suitable crust. This crust is an important factor in reducing wind erosion.

\section{Data availability}

The experimental data used to support the findings of this study are included in the article and readers can access it through the article content. Raw data regarding the findings and any other information can be requested from the corresponding author of the paper via e-mail.

Received: 26 February 2019; Accepted: 16 March 2020;

Published online: 21 April 2020 


\section{References}

1. Rezayi, S. Comparing of the effect of poly-latise polymer and oil mulch on seed germination and plant establishment for biological stabilization of sand hills. Iranian Journal of Range and Desert Research 16(1), 124-136 (2009).

2. Zhang, J. \& Shao, Y. A new parameterization of particle dry deposition over rough surfaces. Atmos. Chem. Phys. 14, 12429-12440 (2014).

3. Shao, Y. Physics and modelling of wind erosion (Vol. 37). Springer Science \& Business Media (2008).

4. Song, Z., Wang, J. \& Wang, S. Quantitative classification of northeast Asian dust events. J. Geophys. Res., 112, D04211 (2007).

5. Zhang, J., Teng, Z., Huang, N., Guo, L. \& Shao, Y. Surface renewal as a significant mechanism for dust emission, Atmos. Chem. Phys. 16, 15517-15528 (2016).

6. Sprigg, W. et al. Regional dust storm modeling for health services: the case for valley fever. J. Aeolian Res. 14, 53-73 (2014).

7. Goudie, A. S. Desert dust and human health disorders. Environ. Int. 63, 101-113 (2014).

8. Hagen, L. J. Erosion by wind: Modeling. In: Lal, R. (ed.). Encyclopedia of Soil Science.2nded, London: Taylor and Francis publishers (2010).

9. Refahi, H. Wind erosion and control. Fifth Edition, Tehran: Tehran University Press. 320 (2009).

10. Ekhtesasi, M.H., Ahmadi, h. Wind erosion, facies, and its damages in the area of Yazd Plain in Ardakan. Iran. J. Nat. Resour. 57 (4) (2004).

11. Vaezi, A. Application of oil mulch in controlling wind erosion and stabilization of sand hills. The second national conference on wind erosion. Phd thesis. Natural Resources in Yazd University (In Persian) (2010).

12. Ghosh, B. N., Dogra, P., Sharma, N. K., Bhattacharyya, R. \& Mishra, P. K. Conservation agriculture impact for soil conservation in maize-wheat cropping system in the Indian sub-Himalayas. International Soil and Water Conservation Research 3(2), 112-118 (2015).

13. Chen, R., Lee, I. \& Zhang, L. Biopolymer stabilization of mine tailings for dust control. J. Geotech. Geoenviron. Eng. 2, 141 (2015).

14. Ekhtesasi, M. \& Haziri, F. Investigating the effect of cement mulch on the stabilization of shifting sands. Pasture and aquaculture, Journal of Natural Resources of Iran 68(4), 739-750 (2015).

15. Khojasteh, D. N., Bahrami, H. A., Kianirad, M. \& Sprigg, W. Using Bio-mulch for Dust Stabilization (Case Study: Semnan Province, Iran). Nat., Environ. Pollut. Technol. 4, 16 (2017).

16. Dermatas, D. \& Meng, X. G. Utilization of fly ash for stabilization/solidification of heavy metal contaminated soils. Eng. Geol. 70, 377-394 (2003)

17. Majdi, H., Karrimian Eghbal, M., Karimzade, H. \& Jalalian, A. The effect of clay mulch on wind erosion yield. Sci. Technol. Agric. Nat. Resour. 10(3), 137-148(2005).

18. Khalili Moghadam, B., Jamili, T., Nadian, H. \& Shahbazi, E. The influence of sugarcane mulch on sand dune stabilization in Khuzestan, the southwest of Iran. Iran Agric. Res. 34(2), 71-80 (2016).

19. Chan, K. Y., Van Zwieten, L., Meszaros, I., Downie, A. \& Joseph, S. Agronomic values of greenwaste biochar as a soil amendment. Soil Res. 45(8), 629-634 (2008).

20. Miri, A., Dragovich, D. \& Dong, Z. Vegetation morphologic and aerodynamic characteristics reduce aeolian erosion. Sci. Rep. 7(1), 12831 (2017).

21. Hosseini, A., Zare, M. \& Zare arnani, M. Use of compost as an anti-erosion agent in wind tunnel. Third National Conference on Wind Erosion and Dustpans in Yazd University of Natural Resources and Natural Resources (2013).

22. Shojaei, S. \& Shojaei, S. Optimization of process variables by the application of response surface methodology for dye removal using nanoscale zero-valent iron. Int. J. Environ. Sci. Technol., 1-10 (2018).

23. Shojaei, S., Shojaei, S. \& Pirkamali, M. Application of Box-Behnken Design Approach for Removal of Acid Black 26 from Aqueous Solution Using Zeolite: Modeling, Optimization, and Study of Interactive Variables. Water Conservation Science and Engineering 4(1), 13-19 (2019).

24. Shojaei, S. \& Shojaei, S. Experimental design and modeling of removal of Acid Green 25 dye by nanoscale zero-valent iron. EuroMediterranean. Journal for Environmental Integration 2(1), 15 (2017).

25. Bhangoo, M. S. K. S. Day, V. R. Sudangunta and v. e. petrucci. Application of poultry manur infiuences Thompson seedless grape production and soil properties. Hort. Sci. 23, 1010-1012 (1988).

26. Moazzemi, N., Beige, N., Ranjpishe, M. Comparison of mulch types on the stabilization of shifting sand. National Seminar on Wind Erosion and Dust Storms of Natural Resources and Agriculture Faculty, Yazd University (2013).

27. Singh, R. P. and Manindra Agrawal. Potential benefits and risks of land application of sewage sludge. Waste Manage. 28.2, 347-358 (2008).

28. Debosz, K., Petersen, S. O., Kure, L. K. \& Ambus, P. Evaluating effects of sewage sludge and household compost on soil physical, chemical and microbiological properties. Appl. Soil Ecol. 19(3), 237-248 (2002).

29. Adelpour, A., Soufi, M. \& Behnia, A. K. Evaluation of the impact of mulches in rainfed farms on doil conservation in the arid and semi-arid region in douth of Iran. Agric. Sci. Natur. Resour. 13(2), 50-57 (2006).

30. Aggelides, S. M. \& Londra, P. A. Effects of compost produced from town wastes and sewage sludge on the physical properties of a loamy and a clay soil. Bioresour. Technol. 71(3), 253-259 (2000).

31. Allahdady, M., Hedjazi, S., Jonoobi, M., Abdolkhani, A. \& Jamalirad, L. Investigation on mechanical-thermal properties of green composite produced from polylactic acid and bagasse pulp fibers. J. For. Wood Prod. 2(70), 333-342 (2017).

32. Farahmehr, F., Khalili Moghadam, B., Shahbazi, E. \& Rahnama., M. Comparison of the Environmentally Friendly Mulches Efficiency for Sand Dune Stabilization in Ahvaz. Iran. J. Soil Water Res. 4(29), 463-474 (2016).

33. Sharratt, B. S., Lindstrom, M. J., Benoit, G. R., Young, R. A. \& Wilts, A. Runoff and soil erosion during spring thaw in the northern US Corn Belt. J. Soil Water Conserv 55(4), 487-494 (2000).

\section{Author contributions}

S.S. wrote the manuscript with contributions from all the co-authors. All the authors participated in the development of the study and the experiments.

\section{Competing interests}

The authors declare no competing interests.

\section{Additional information}

Correspondence and requests for materials should be addressed to M.A.H.A.

Reprints and permissions information is available at www.nature.com/reprints.

Publisher's note Springer Nature remains neutral with regard to jurisdictional claims in published maps and institutional affiliations. 
(c) (i) Open Access This article is licensed under a Creative Commons Attribution 4.0 International License, which permits use, sharing, adaptation, distribution and reproduction in any medium or format, as long as you give appropriate credit to the original author(s) and the source, provide a link to the Creative Commons license, and indicate if changes were made. The images or other third party material in this article are included in the article's Creative Commons license, unless indicated otherwise in a credit line to the material. If material is not included in the article's Creative Commons license and your intended use is not permitted by statutory regulation or exceeds the permitted use, you will need to obtain permission directly from the copyright holder. To view a copy of this license, visit http://creativecommons.org/licenses/by/4.0/.

(C) The Author(s) 2020 